\title{
Low-level laser therapy as a treatment for chronic pain
}

\author{
J. Derek Kingsley ${ }^{*}$, Timothy Demchak ${ }^{2}$ and Reed Mathis ${ }^{3}$ \\ ${ }_{1}^{1}$ Human Performance and Autonomic Studies Laboratory, Department of Exercise Physiology, Kent State University, Kent, OH, USA \\ ${ }^{2}$ Department of Applied Medicine, Indiana State University, Terre Haute, IN, USA \\ ${ }^{3}$ Reed Mathis DC, Tallahassee, FL, USA \\ ${ }^{*}$ Correspondence: jkingsle@kent.edu
}

Edited by:

Evangelos A. Christou, University of Florida, USA

Reviewed by:

Kelly Anne Kaiser, University of Calgary, Canada

Keywords: fibromyalgia, myofascial pain syndrome, class Illb laser, analgesia

Chronic pain is defined as pain that persists for greater than 12 weeks (TaskForce, 1994) and currently affects roughly $30 \%$ of the population in the United States (Johannes et al., 2010). The most common method for managing chronic pain has traditionally been pharmacological (Nalamachu, 2013). These treatments often include non-steroidal anti-inflammatory drugs (NSAIDS), opioids, acetaminophen, and anticonvulsants (Nalamachu, 2013). Alternative medicine is now also being used more frequently to treat chronic pain and may consist of acupuncture (McKee et al., 2013), Tai Chi (Wang et al., 2010; Wang, 2012), and lowlevel laser therapy (LLLT) (Enwemeka et al., 2004; Ay et al., 2010). The focus of this manuscript is to highlight the physiological aspects of LLLT, and to discuss its application for those suffering from chronic pain, alone and in combination with exercise. It will also provide justification for the use of LLLT using specific data and case studies from the existing literature which have resulted in positive outcomes for those suffering from chronic pain.

The physiological mechanisms of LLLT are not well-understood and the mechanisms tend to be very broad (Yamamoto et al., 1988; Kudoh et al., 1989; Campana et al., 1993; Sakurai et al., 2000; Chow et al., 2007; Moriyama et al., 2009; CidralFilho et al., 2014). One hypothesis is that there may be an increase in nociceptive threshold after LLLT resulting in neural blockade, specifically an inhibition of $\mathrm{A}$ and $\mathrm{C}$ neural fibers (Kudoh et al., 1989; Chow et al., 2007). This inhibition may be mediated by altering the axonal flow (Chow et al., 2007) or by inhibiting neural enzymes (Kudoh et al., 1989). In addition, data suggests an increase in endorphin production (Yamamoto et al., 1988) and opioidreceptor binding via opioid-containing leukocytes with LLLT (Cidral-Filho et al., 2014). LLLT may also mimic the effects of anti-inflammatory drugs by attenuating levels of prostaglandin-2 (PGE2) (Campana et al., 1993) and inhibiting cyclooxygenase-2 (COX-2) (Sakurai et al., 2000). In addition, data have suggested that LLLT may augment levels of nitric oxide, a powerful vasodilator, which would in turn act to increase blood flow and assist with healing (Samoilova et al., 2008; Moriyama et al., 2009; Cidral-Filho et al., 2014; Mitchell and Mack, 2013). While the mechanisms have not been completely explained, it is clear that LLLT may have an analgesic effect.

Studies have demonstrated that LLLT may have positive effects on symptomology associated with chronic pain (Fulop et al., 2010; Hsieh and Lee, 2013); however this finding is not universal (Ay et al., 2010). A meta-analysis utilizing 52 effect sizes from 22 articles on LLLT and pain from Fulop et al. (2010) demonstrated an overall effect size of 0.84 . This would be classified as a large effect size and suggests a strong inclination for the use of LLLT to reduce chronic pain. Twenty-two studies were utilized with doses ranging from 1 to $30 \mathrm{~J} / \mathrm{cm}^{2}$. On the other hand, a meta-analysis from Gam et al. (1993) demonstrated no effect of LLLT on musculoskeletal pain but this study was published over 20 years ago when LLLT was just emerging. More recently data from
Ay et al. (2010) have reported no difference in chronic pain compared to placebo using twice weekly treatment 5 days a week for 3 weeks. Treatment consisted of a total energy of $40 \mathrm{~J} / \mathrm{cm}^{2}(850 \mathrm{~nm}, 100 \mathrm{mV}$, a treatment spot area of $0.07 \mathrm{~cm}^{2}, 4 \mathrm{~min}$ over each of the four different points). Taken together, it is hard to assess whether LLLT is an effective modality. However, it is clear that LLLT may be effective in treating chronic pain in many individuals and should not be overlooked as a treatment modality.

A systematic review and meta-analysis from 16 randomized control studies on LLLT and neck pain (Chow et al., 2009) interpreted the analysis that LLLT caused an immediate decrease in pain for acute neck pain and up to 22 weeks post in chronic neck pain patients. Recently, in a double blinded placebo control study Leal et al. (2014) reported a decrease pain and increase in function in patients with knee pain.

One issue with these meta-analyses is that participants were grouped together, under the heading of chronic pain. However, chronic pain has different manifestations which inhibit the ability to make general observations. Separate subheadings of chronic pain may include but are not limited to chronic neck pain and lower back pain, myofascial pain syndrome, and fibromyalgia. A meta-analysis by Gross et al. (2013) worked to separate out the effect of LLLT on a variety of different conditions. Based on their review, the effect of LLLT on chronic neck pain has a moderate level of evidence for effectiveness when using 830 or $940 \mathrm{~nm}$ but not $632.8 \mathrm{~nm}$. However, 
it was mentioned that the trials investigating chronic neck pain and LLLT failed to blind participants which may limit the application of the data. The authors also included the effect of LLLT on myofascial pain syndrome and reported that the data are mixed and evidence is lacking. In addition, LLLT treatments have been reported to be effective for decreasing pain and increasing function in other chronic pain pathologies including fibromyalgia syndrome (Gur et al., 2002a,b; Armagan et al., 2006; Moore and Demchak, 2012).

Studies that examine the use of LLLT combined with exercise seem to have merit, as exercise is a staple of rehabilitation. Interestingly, Djavid et al. (2007) and Gur et al. (2003) both combined LLLT with exercise and each reported no additional effect of exercise in patients with chronic lower back pain. Djavid et al. utilized $27 \mathrm{~J} / \mathrm{cm}^{2}$ of total energy $(810 \mathrm{~nm}$, $50 \mathrm{~mW}$ with an aperture of $0.2211 \mathrm{~cm}^{2}$, 8 points total) while Gur et al. utilized $1 \mathrm{~J} / \mathrm{cm}^{2}(10 \mathrm{~W}$ with an aperature of $10.1 \mathrm{~cm}^{2}, 4 \mathrm{~min}$ per point) for each of the 8 points. Matsutani et al. (2007) combined stretching exercise with LLLT $(830 \mathrm{~nm}$, $30 \mathrm{~mW}$ with an intensity of $3 \mathrm{~J} / \mathrm{cm}^{2}$ over 18 tender points) in 20 women with fibromyalgia. There was no additive effect of combining stretching with LLLT in this study. Both groups reported reductions in pain scores and fatigue. Ultimately, the data are scarce and more are needed to truly understand the implications of LLLT when combined with exercise.

What tends to plague research using LLLT as a treatment modality is that there is no standard of care. Studies differ in overall dosage and wavelength which limits the ability to accurately draw conclusions. Currently, there are also no long-term studies that have evaluated LLLT. Pain is a very complex condition that manifests itself in a variety of different forms. Perhaps there is no set standard of care that will encompass everyone's needs. However, it is clear that LLLT may be beneficial for many individuals suffering from pain, regardless of the condition that is causing it.

\section{REFERENCES}

Armagan, O., Tascioglu, F., Ekim, A., and Oner, C. (2006). Long-term efficacy of low level laser therapy in women with fibromyalgia: a placebo-controlled study. J. Back Musculoskelet. Rehabil. 19, 135-140.

Ay, S., Dogan, S. K., and Evcik, D. (2010). Is lowlevel laser therapy effective in acute or chronic low back pain? Clin. Rheumatol. 29, 905-910. doi: 10.1007/s10067-010-1460-0

Campana, V., Catsel, A., Vidal, A. E., Juri, H., and Palma, J. A. (1993). Prostaglandin E2 in experimental arthritis of rats irradiated with He-Nelaser. J. Clin. Laser Med. Surg. 11, 79-81.

Chow, R. T., David, M. A., and Armati, P. J. (2007). $830 \mathrm{~nm}$ laser irradiation induces varicosity formation, reduces mitochondrial membrane potential and blocks fast axonal flow in small and medium diameter rat dorsal root ganglion neurons: implications for the analgesic effects of $830 \mathrm{~nm}$ laser. J. Peripher. Nerv. Syst. 12, 28-39. doi: 10.1111/j.1529-8027.2007.00114.x

Chow, R. T., Johnson, M. I., Lopes-Martins, R. A., and Bjordal, J. M. (2009). Efficacy of low-level laser therapy in the management of neck pain: a systematic review and meta-analysis of randomised placebo or active-treatment controlled trials. Lancet 374, 1897-1908. doi: 10.1016/S01406736(09)61522-1

Cidral-Filho, F. J., Mazzardo-Martins, L., Martins, D. F., and Santos, A. R. S. (2014). Light-emitting diode therapy induces analgesia in a mouse model of postoperative pain through activation of peripheral opioid receptors and the L-arginine/nitric oxide pathway. Lasers Med. Sci. 29, 695-702. doi: 10.1007/s10103-013-1385-3

Djavid, G. E., Mehrdad, R., Ghasemi, M., Hasan-Zadeh, H., Sotoodeh-Manesh, A., and Pouryaghoub, G. (2007). In chronic low back pain, low level laser therapy combined with exercise is more beneficial than exercise alone in the long term: a randomised trial. Aust. J. Physiother. $53, \quad 155-160$. doi: 10.1016/S0004-9514(07) $70022-3$

Enwemeka, C. S., Parker, J. C., Dowdy, D. S., Harkness, E. E., Sanford, L. E., and Woodruff, L. D. (2004). The efficacy of low-power lasers in tissue repair and pain control: a meta-analysis study. Photomed. Laser Surg. 22, 323-329. doi: 10.1089/pho.2004.22.323

Fulop, A. M., Dhimmer, S., Deluca, J. R., Johanson, D. D., Lenz, R. V., Patel, K. B., et al. (2010). A meta-analysis of the efficacy of laser phototherapy on pain relief. Clin. J. Pain 26, 729-736. doi: 10.1097/AJP.0b013e3181f09713

Gam, A. N., Thorsen, H., and Lonnberg, F. (1993). The effect of low-level laser therapy on musculoskeletal pain: a meta-analysis. Pain 52, 63-66. doi: 10.1016/0304-3959(93)90114-5

Gross, A. R., Dziengo, S., Boers, O., Goldsmith, C. H., Graham, N., Lilge, L., et al. (2013). Low Level Laser Therapy (LLLT) for neck pain: a systematic review and meta-regression. Open Orthop. J. 7, 396-419. doi: 10.2174/1874325001307010396

Gur, A., Karakoc, M., Cevik, R., Nas, K., Sarac, A. J., and Karakoc, M. (2003). Efficacy of low power laser therapy and exercise on pain and functions in chronic low back pain. Lasers Surg. Med. 32, 233-238. doi: 10.1002/lsm.10134

Gur, A., Karakoc, M., Nas, K., Cevik, R., Sarac, J., and Ataoglu, S. (2002a). Effects of low power laser and low dose amitriptyline therapy on clinical symptoms and quality of life in fibromyalgia: a single-blind, placebo-controlled trial. Rheumatol. Int. 22, 188-193. doi: 10.1007/s00296-002-0221-z

Gur, A., Karakoc, M., Nas, K., Cevik, R., Sarac, J., and Demir, E. (2002b). Efficacy of low power laser therapy in fibromyalgia: a single-blind, placebocontrolled trial. Lasers Med. Sci. 17, 57-61. doi: 10.1007/s10103-002-8267-4

Hsieh, R., and Lee, W. (2013). Short-term therapeutic effects of 890-nanometer light therapy for chronic low back pain: a double-blind randomized placebo-controlled study. Lasers Med. Sci. 29, 671-679. doi: 10.1007/s10103-13-1378-2

Johannes, C. B., Le, T. K., Zhou, X., Johnston, J. A., and Dworkin, R. H. (2010). The prevalence of chronic pain in United States adults: results of an Internet-based survey. J. Pain 11, 1230-1239. doi: 10.1016/j.jpain.2010.07.002

Kudoh, C., Inomata, K., Okajima, K., Motegi, M., and Ohshiro, T. (1989). Effects of $830 \mathrm{~nm}$ gallium aluminum arsenide diode laser radition on rat saphenous nerve sodium-potassium-adenosine triphosphate activity: a possible pain attenuation mechanism explained. Laser Surg. 1, 63-67.

Leal, E. C., Johnson, D. S., Saltmache, A., and Demchak, T. (2014). Adjunctive use of combination of super-pulsed laser and light-emitting diodes phototherapy on nonspecific knee pain: double-blinded randomized placebo-controlled trial. Lasers Med. Sci. doi: 10.1007/s10103-0141592-6. [Epub ahead of print].

Matsutani, L. A., Marques, A. P., Ferreira, E. A. Assumpcao, A., Lage, L. V., Casarotto, R. A., et al. (2007). Effectiveness of muscle stretching exercises with and without laser therapy at tender points for patients with fibromyalgia. Clin. Exp. Rheumatol. $25,410-415$.

McKee, M. D., Kligler, B., Fletcher, J., Biryukov, F., Casalaina, W., Anderson, B., et al. (2013). Outcomes of acupuncture for chronic pain in urban primary care. J. Am. Board Fam. Med. 26, 692-700. doi: 10.3122/jabfm.2013.06.130003

Mitchell, U. H., and Mack, G. L. (2013). Lowlevel laser treatment with near-infrared light increases venous nitric oxide levels acutely: a single-blind, randomized clinical trial of efficacy. Am. J. Phys. Med. Rehabil. 92, 151-156. doi: 10.1097/PHM.0b013e318269d70a

Moore, J., and Demchak, T. J. (2012). Treatment of fibromyalgia syndrome with low level laser therapy. Int. J. Athl. Ther. Train. 17, 28-34.

Moriyama, Y., Nguyen, J., Akens, M., Moriyama, E. H., and Lilge, L. (2009). In vivo effects of low-level laser therapy on inducible nitric oxide synthase. Laser Surg. Med. 41, 227-231. doi: 10.1002/lsm.20745

Nalamachu, S. (2013). An overview of pain management: the clinical efficacy and value of treatment. Am. J. Manag. Care 19, s261-s266.

Sakurai, Y., Yamaguchi, M., and Abiko, Y. (2000). Inhibitory effect of low-level laser irradiation on LPS-stimulated prostaglandin E2 production and cyclooxygenase-2 in human gingival fibroblasts. Eur. J. Oral Sci. 108, 29-34. doi: 10.1034/j.16000722.2000.00783.x

Samoilova, K. A., Zhevago, N. A., Petrishchev, N. N., and Zimin, A. A. (2008). Role of nitric oxide in the visible light-induced rapid increase of human skin microcirculation at the local and systemic levels: II. healthy volunteers. Photomed. 
Laser Surg. 26, 443-449. doi: 10.1089/pho. 2007.2205

Task-Force. (1994). "Part III: pain terms, a current list with definitions and notes on usage," in Classification of Chronic Pain, 2nd Edn. (Seattle, WA: IASP Press), 209-214.

Wang, C. (2012). Role of Tai Chi in the treatment of rheumatologic diseases. Curr. Rheumatol. Rep. 14, 598-603. doi: 10.1007/s11926-012-0294-y

Wang, C., Schmid, C. H., Rones, R., Kalish, R., Yinh, J., Goldenberg, D. L., et al. (2010). A randomized trial of tai chi for fibromyalgia. N. Engl. J. Med. 363, 743-754. doi: 10.1056/NEJMoa0912611
Yamamoto, H., Ozaki, A., Iguchi, N., and Kinoshita, S. (1988). Antinociceptive effect of laser irradiaion on Hoku points in rats. Pain Clin. 8, 43-48.

Conflict of Interest Statement: The authors declare that the research was conducted in the absence of any commercial or financial relationships that could be construed as a potential conflict of interest.

Received: 22 May 2014; accepted: 27 July 2014; published online: 19 August 2014.

Citation: Kingsley JD, Demchak T and Mathis R (2014) Low-level laser therapy as a treatment for chronic pain. Front. Physiol. 5:306. doi: 10.3389/fphys. 2014.00306

This article was submitted to Exercise Physiology, a section of the journal Frontiers in Physiology.

Copyright (c) 2014 Kingsley, Demchak and Mathis. This is an open-access article distributed under the terms of the Creative Commons Attribution License (CC BY). The use, distribution or reproduction in other forums is permitted, provided the original author(s) or licensor are credited and that the original publication in this journal is cited, in accordance with accepted academic practice. No use, distribution or reproduction is permitted which does not comply with these terms. 